\title{
Investigação de Baixa Estatura: Aspectos Clínicos, Laboratoriais e Moleculares da Insensibilidade ao Hormônio de Crescimento
}

\section{caso especial}

\section{Alexander Augusto de lima Jorge}

Unidade de Endocrinologia do

Desenvolvimento e Laboratório de Hormônios e Genética Molecular - LIM/42, Disciplina de Endocrinologia do

Departamento de Clínica Médica do Hospital das Clínicas da Faculdade de Medicina da Universidade de São Paulo (HC-FMUSP), SP, Brasil (AALJ);

\section{EDITORA CONVIDADA:}

Maria Adelaide Albergaria Pereira Serviço de Endocrinologia e Metabologia do HC-FMUSP, SP, Brasil (MAAP)

Recebido em 37/1/2008 Aceito em 28/4/2008

\author{
RESUMO
}

Neste artigo são descritos os aspectos clínicos, laboratoriais e genéticos da investigação da baixa estatura, dando ênfase para o diagnóstico da insensibilidade ao hormônio de crescimento (IGH). O paciente apresentado possuía características clínicas típicas de pacientes com IGH e em idade pré-púbere seus achados laboratoriais eram compatíveis com este diagnóstico (IGF-1 e IGFBP3 baixos, GH basal e pós-estímulo elevados). No entanto, quando avaliado durante a puberdade, as dosagens de IGF-1 e IGFBP-3 foram normais, dificultando o diagnóstico. $O$ estudo molecular identificou mutação no exon 7 do gene do receptor do hormônio de crescimento (S226I). Discutiram-se os passos realizados para identificar a mutação e demonstrar que ela é responsável pelo fenótipo observado no paciente. Também será feita revisão dos casos de IGH descritos no Brasil e dos novos defeitos moleculares descritos nesta doença. (Arq Bras Endocrinol Metab 2008; 52/6:1056-1065)

Descritores: Transtornos do crescimento; Receptores de GH; Deficiência de $\mathrm{GH}$; Baixa estatura; Insensibilidade ao GH; Síndrome de Laron

\section{ABSTRACT}

Short Stature Investigation: Clinical, Laboratorial and Genetic Aspects Concerning the Trowth Hormone Insensitivity (GHI)

It is reported in this study the clinical, laboratory and genetic aspects of short stature investigation with emphasis to the diagnostic approach of growth hormone insensitivity (GHI). This patient in case presented typical clinical features of $\mathrm{GHI}$ and his laboratory findings at prepubertal age were typical of those observed in GHI patients (low IGF-1 and IGFBP-3 levels, with high basal and stimulated GH levels). However, during the puberty, he presented normal IGFBP-3 and IGF-1 levels that hindered the diagnosis. The molecular study disclosed a mutation in exon 7 of growth hormone receptor gene (S226I). The steps that demonstrated the causative effect of this mutation are shown here, and also a review of Brazilian GHI cases is given and new molecular defects in this field are discussed as well. (Arq Bras Endocrinol Metab 2008; 52/6:1056-1065)

Keyword: Growth disorders; GH receptors; GH deficiency; Short stature; Growth hormone insensitivity; Laron syndrome; Short stature

\section{INTRODUÇÃO}

$\mathrm{O}$ OBJETIVO DESTA APRESENTAÇ̃̃o é discutir a investigação da baixa estatura do ponto de vista clínico, molecular e genético. Antevendo uma medicina que seja a fusão da clínica com a genética e a biologia molecular, será dado destaque às novas descobertas de defeitos moleculares na área de insensibilidade ao hormônio de crescimento (IGH) e como o estudo molecular participa da investigação de causas genéticas de baixa estatura. 


\section{RELATO DO CASO}

$\mathrm{O}$ paciente procurou atendimento médico, em outro serviço, aos 10,6 anos idade com história de baixa estatura desde o nascimento, que ocorreu aos nove meses de gestação, via cesariana em virtude de apresentação transversa, sem complicações. $\mathrm{O}$ peso ao nascer era de $2 \mathrm{~kg}(Z=-2,9)$ e foi observado micropênis. Apresentou icterícia neonatal, com início no segundo dia de vida e que durou uma semana e não havia história sugestiva de hipoglicemia. Apesar do crescimento lento e do atraso no desenvolvimento dentário, não apresentava doenças crônicas e teve desenvolvimento neuropsicomotor normal. Os pais são primos de segundo grau. O pai tem $168 \mathrm{~cm}(\mathrm{Z}=-1,0)$ e a mãe $148 \mathrm{~cm}(\mathrm{Z}=$ $-2,3)$, resultando altura-alvo de $164 \mathrm{~cm}$. Apresenta oito irmãos de altura normal $(\mathrm{Z}$ da altura variando de $-1,9$ a $-0,3)$. Ao exame físico demonstrava baixa estatura proporcional, com altura de $96,2 \mathrm{~cm}(Z=-6,7)$ e peso de $18,4 \mathrm{~kg}(\mathrm{Z}$ do IMC $=+1,3)$. A idade óssea era de 4 anos. O paciente encontrava-se pré-púbere e apresentava as seguintes características clínicas: fronte olímpica, nariz em sela, hipoplasia da face, micropênis e distribuição centrípeta de gordura.

A história clínica e o exame físico deste paciente sugeriam o diagnóstico de deficiência de GH (1). A história de consangüinidade familiar indicava a possibilidade de causa genética autossômica recessiva de deficiência isolada de GH ou de insensibilidade a este hormônio. Em primeira avaliação laboratorial, feita aos 10,7 anos, verificou-se valores baixos de IGF-1 com hiper-resposta do GH no teste da clonidina (Tabela 1). Optou-se, inicialmente, pela administração de $\mathrm{GH}$ recombinante humano (hGH), mas como não apresentou resposta clínica, este tratamento foi abandonado. O paciente foi encaminhado para o Serviço de Endocrinologia e Metabologia do Hospital das Clínicas da Faculdade de Medicina da Universidade de São Paulo aos 15,7 anos de idade com altura de $124 \mathrm{~cm}(\mathrm{Z}=$ $-6,7)$, peso de $43,4 \mathrm{~kg}(\mathrm{ZIMC}=+2,3)$, idade óssea de 13 anos e sinais iniciais de puberdade (volume testicular de 4 $\mathrm{mL}$ e pelos pubianos estádio 2 de Tanner). Nessa época, apresentava valores normais de IGFBP-3 $(3,5 \mathrm{mg} / \mathrm{L}, \mathrm{Z}=$ $-0,5)$ e concentrações pouco reduzidas de IGF-1 (151 $\mu \mathrm{g} / \mathrm{L}, \mathrm{Z}=-2)$ (Tabela $\mathrm{l}$ ).

Tabela 1. Avaliação laboratorial do paciente com IGH por mutação S226l.

\begin{tabular}{|c|c|c|c|c|c|c|c|c|}
\hline Condição & $\begin{array}{c}\text { Idade } \\
\text { anos }\end{array}$ & $\begin{array}{c}\mathrm{GH} \\
\mu \mathrm{g} / \mathrm{L}\end{array}$ & $\begin{array}{c}\text { GHBP } \\
\text { pmol/L }\end{array}$ & $\begin{array}{l}\text { IGF-I } \\
\mu g / L\end{array}$ & $\begin{array}{c}\text { IGFBP-3 } \\
\mathrm{mg} / \mathrm{L}\end{array}$ & $\begin{array}{l}\text { LH } \\
\mathrm{U} / \mathrm{L}\end{array}$ & $\begin{array}{l}\text { FSH } \\
\text { U/L }\end{array}$ & $\begin{array}{l}\text { Testo } \\
\text { ng/dL }\end{array}$ \\
\hline Basal (pré-púbere)* & 10,7 & $1,0-1,6$ & & $<18$ & 1,1 & $<0,6$ & $<1,0$ & $<14$ \\
\hline Após clonidina & & 58,5 & & & & & & \\
\hline Basal (início de puberdade) & 15,7 & $4-15$ & & 151 & 3,5 & 6,3 & 9,8 & 193 \\
\hline Pico após hipoglicemia & & 33 & & & & & & \\
\hline 28 dias após o início de aGnRH & 15,9 & 0,3 & $<125$ & 173 & 3,5 & $<0,6$ & $<1,0$ & $<14$ \\
\hline 4 meses de tratamento com aGnRH & 16,2 & $0,2-0,4$ & 132 & 100 & 3,1 & $<0,6$ & $<1,0$ & $<14$ \\
\hline 5 meses de tratamento com aGnRH & 16,2 & $0,2-0,5^{\star *}$ & 147 & 128 & 2,6 & $<0,6$ & $<1,0$ & $<14$ \\
\hline Após clonidina em uso de aGnRH & & 21 & & & & & & \\
\hline 11 meses de tratamento com aGnRH & 16,7 & $0,1-0,9^{* *}$ & & 81 & 2,7 & $<0,6$ & $<1,0$ & $<14$ \\
\hline 14 meses de tratamento com aGnRH & 17,0 & 0,2 & & 83 & 1,8 & 0,9 & 1,4 & \\
\hline $\begin{array}{l}\text { Imediatamente após a suspensão do } \\
\text { aGnRH }\end{array}$ & 17,7 & $11,8-15,8$ & & 98 & 3,3 & 0,7 & 1,4 & 37 \\
\hline Sem tratamento & 18,8 & 3,1 & & 159 & 3,7 & 0,6 & 1,9 & 35 \\
\hline Sem tratamento & 19,2 & 0,3 & & 291 & 3,7 & 9,7 & 9,2 & 486 \\
\hline Sem tratamento & 19,6 & 0,6 & & 203 & 3,9 & 7,0 & 5,9 & 623 \\
\hline \multirow[t]{2}{*}{ Valores normais } & & & $431-1.892$ & 10 anos: $37-45$ & 10 anos: $1,8-5,7$ & \multicolumn{3}{|c|}{ Pré-púbere } \\
\hline & & & & $\begin{array}{l}15 \text { anos: } 335-802 \\
18 \text { anos: } 206-942\end{array}$ & $\begin{array}{l}15 \text { anos: } 3,4-6,8 \\
18 \text { anos: } 3,2-7,1\end{array}$ & $<0,6$ & $<3,2$ & $<14$ \\
\hline
\end{tabular}




\section{Investigação laboratorial de baixa estatura}

A investigação laboratorial de qualquer paciente com baixa estatura deve ser bastante ampla, permitindo afastar outras causas de baixa estatura que podem estar sendo encobertas (Tabela 2). O paciente em discussão apresentava discreta anemia hipocrômica normocítica $(\mathrm{Hg}=11,4 \mathrm{~g} / \mathrm{dL} ; \mathrm{VCM}=80 \mathrm{fL}, \mathrm{CHCM}=31 \mathrm{~g} / \mathrm{dL})$ e o exame protoparasitológico revelava giardíase. Entretanto, como apenas essas alterações não puderam explicar a baixa estatura importante e os estigmas sugestivos de deficiência de $\mathrm{GH}$, foi realizada investigação laboratorial do eixo GH/IGF-1.

Tabela 2. Exames rotineiramente utilizados na investigação da baixa estatura.

\begin{tabular}{ll}
\hline Exame & Objetivo \\
\hline Hemograma & $\begin{array}{l}\text { Afastar a presença de } \\
\text { anemias }\end{array}$ \\
$\begin{array}{l}\text { Velocidade de } \\
\text { hemossedimentação }\end{array}$ & $\begin{array}{l}\text { Afastar doenças inflamatórias } \\
\text { crônicas }\end{array}$ \\
\hline Albumina e ferritina & Avaliar o estado nutricional \\
\hline Transaminases & $\begin{array}{l}\text { Afastar hepatopatias } \\
\text { crônicas }\end{array}$ \\
\hline $\begin{array}{l}\text { Uréia, creatinina, Na }{ }^{+}, K^{+}, \\
\text {gasometria venosa e }\end{array}$ & Afastar doenças renais \\
urina tipo I & $\begin{array}{l}\text { Afastar raquitismo e outras } \\
\text { doenças do metabolismo } \\
\text { Cálcio, fósforo e fosfatase }\end{array}$ \\
\hline $\begin{array}{l}\text { Anticorpo antiendomísio, } \\
\text { antigliadina ou } \\
\text { antitransglutaminase }\end{array}$ & Afastar doença celíaca \\
\hline Protoparasitológico & Afastar verminose \\
\hline TSH e T4L & Avaliar a função tireoidiana \\
\hline RX de mãos e punhos & Determinar a idade óssea \\
\hline IGF-1 e IGFBP-3 (GH) & Avaliar o eixo GH-IGF-1 \\
\hline $\begin{array}{l}\text { Cariótipo (em todas as } \\
\text { meninas) }\end{array}$ & Afastar a síndrome de Turner \\
\hline
\end{tabular}

Por causa da natureza pulsátil da secreção de $\mathrm{GH}$, a dosagem de GH basal de maneira isolada traz poucas informações na investigação da baixa estatura. Já os peptídeos, IGF-1, IGFBP-3 e a subunidade ácido-lábil (ALS) apresentam concentrações sangüíneas relativamente estáveis em 24 horas e refletem a secreção de GH. Assim sendo, a avaliação do eixo GH/IGF-1 deve ser inicialmente realizada por meio das dosagens de IGF-1 e IGFBP-3. Os pacientes com concentrações destes dois peptídeos inferiores aos valores normais para a idade e o sexo devem ser investigados quanto à secreção de $\mathrm{GH}$, para o diagnóstico de deficiência ou insensibilidade ao $\mathrm{GH}$.

Os dados laboratoriais do paciente em discussão estão na Tabela 1. Aos 10,7 anos, as dosagens de IGF-1 e IGFBP-3 eram -6 e $-4,5$ desvios-padrão em relação à média para idade e sexo, respectivamente. As concentrações tão baixas de IGF-1 e IGFBP-3 são encontradas, quase com exclusividade, na deficiência grave de GH ou na insensibilidade ao GH. O diagnóstico diferencial entre essas duas condições pode ser feito pela determinação do GH basal, que se encontra elevado nos estados de insensibilidade, na maioria dos casos. Todavia, no paciente em análise, os valores de GH basal não auxiliaram no diagnóstico diferencial e a secreção de GH foi avaliada pelo teste da clonidina, durante o qual, as concentrações de $\mathrm{GH}$ atingiram valores elevados $(58,5 \mu \mathrm{g} / \mathrm{L})$, excluindo deficiência de $\mathrm{GH}$ e indicando a presença de insensibilidade ao $\mathrm{GH}$. $\mathrm{O}$ quadro clínico compatível com deficiência de GH associado à história de pais consangüíneos, presença de concentrações baixas de IGF-1 e IGFBP-3, resposta exagerada da secreção de $\mathrm{GH}$ no teste de liberação indicam o diagnóstico de insensibilidade ao $\mathrm{GH}$ (IGH).

\section{INSENSIBILIDADE AO GH (IGH)}

A IGH é definida como a inabilidade de as células-alvo responderem normalmente ao $\mathrm{GH}$ endógeno, e foi descrita, pela primeira vez, na década de 1960, por Laron (2). O quadro clássico de IGH, que ficou conhecido como síndrome de Laron, é caracterizado pela presença de sinais e sintomas encontrados na deficiência completa de GH (baixa estatura importante, face típica, micropênis, obesidade centrípeta e história de hipoglicemia) e dosagem de GH normal ou elevada. A apresentação clínica e laboratorial da IGH é um espectro, em que em um extremo tem-se os pacientes com o fenótipo típico descrito por Laron e no outro extremo tem-se crianças com formas atípicas de IGH que podem ser, clínica e laboratorialmente, confundidas com crianças com baixa estatura idiopática $(3,4)$. As características fenotípicas mais relevantes da IGH estão relacionadas no Tabela 3. 
Tabela 3. Características fenotípicas associadas a IGH.

Herança autossômica recessiva na grande maioria dos casos
Presença de consangüinidade freqüente
Gestação e parto sem anormalidades
Peso ao nascimento médio de $2.500 \mathrm{~g}$
Comprimento ao nascimento médio de $44 \mathrm{~cm}$
Baixa estatura pós-natal importante
Formas clássicas: Z altura mediana = -6,7 (-3 a -9)
Formar atípicas: Z altura mediana = -4,6 (-2 a -7)
Altura adulta sem tratamento
$119-142 \mathrm{~cm}$ para homens
108-136 cm para mulheres
Aumento da relação massa gorda/magra e tendência à
obesidade
Características clínicas nas formas clássicas: cabelos finos
e esparsos, hipoplasia de face, fronte olímpica, esclera
azulada, nariz em sela, voz aguda e infantil, mãos e pés
pequenos, atraso no fechamento das fontanelas, atraso
na dentição, micropênis (41\%-69\%)
Hipoglicemia (26\%-75\% dos casos, principalmente na
infância)
Atraso importante da idade óssea
Atraso no início da puberdade

Os diagnósticos clínico e laboratorial da IGH são feitos utilizando os critérios de Blum e cols., e a pontuação $\geq 5$ indica IGH (5) (Tabela 4). Existe grande variabilidade nas concentrações de GH, IGF-l e IGFBP-3 entre pacientes com IGH. Os pacientes com formas atípicas, que constituem um grupo com maior dificuldade diagnóstica, apresentam valores significativamente mais baixos de $\mathrm{GH}$ e mais elevados dos peptídeos IGF-1 e IGFBP-3, quando comparados com os pacientes com a forma clássica de IGH $(3,6)$. A GHBP, ou proteína carreadora do GH, encontra-se reduzida ou indetectável em $75 \%$ dos pacientes (7). A GHBP é produzida pela clivagem da porção extracelular do receptor do GH (GHR) e reflete a expressão deste nos tecidos periféricos $(8)$.

Tabela 4. Critérios de Blum e cols. para o diagnóstico da IGH forma clássica (5).

\begin{tabular}{|c|c|c|}
\hline Parâmetro & Critério & Pontuação \\
\hline Z da altura & $<-3 \mathrm{DP}$ & 1 \\
\hline $\begin{array}{l}\text { GH basal aleatório (valor } \\
\text { mínimo) }\end{array}$ & $>4 \mu \mathrm{g} / \mathrm{L}$ & 1 \\
\hline Z do IGF-I basal & $<-2 \mathrm{DP}$ & 1 \\
\hline Z do IGFBP-3 basal & $<-2 \mathrm{DP}$ & 1 \\
\hline $\begin{array}{l}\text { Incremento de |GF-I durante o } \\
\text { teste de geração }\end{array}$ & $<15 \mu \mathrm{g} / \mathrm{L}$ & 1 \\
\hline $\begin{array}{l}\text { Incremento de IGFBP-3 } \\
\text { durante o teste de geração }\end{array}$ & $<0,4 \mathrm{mg} / \mathrm{L}$ & 1 \\
\hline GHBP & $\begin{array}{l}\text { Niveis baixos } \\
\text { ou } \\
\text { indetectáveis }\end{array}$ & 1 \\
\hline
\end{tabular}

O teste fundamental no diagnóstico de IGH é o de geração de IGF-1 e IGFBP-3, que consiste em observar se existe ou não elevação nas concentrações destes peptídeos após o uso de GH exógeno. O teste de geração consiste de injeções subcutâneas de hGH na dose de 33 $\mu \mathrm{g} / \mathrm{kg}$ de peso (ou $0,1 \mathrm{U} / \mathrm{kg}$ ) por quatro noites consecutivas, com coletas de sangue periférico para dosagem de IGF-1 e IGFBP-3 na manhã antes da primeira aplicação de hGH e 12 horas após a última (5). É importante destacar que o teste de geração de IGF-1 e IGFBP-3 apresenta grande variabilidade de resposta entre os indivíduos (9) e baixa reprodutibilidade em crianças sem IGH (10). Assim sendo, principalmente quando são avaliadas crianças sem as características típicas de IGH, é necessário confirmar, em dois testes de geração, a ausência de incremento de IGF-1 e IGFBP-3 antes de se estabelecer o diagnóstico clínico de IGH (10).

No paciente em discussão, com fenótipo clássico de síndrome de Laron e valores elevados de $\mathrm{GH}$, chamava a atenção que ele apresentasse, aos 15,7 anos de idade, concentrações normais de IGFBP-3 $(3,5 \mathrm{mg} / \mathrm{L}, \mathrm{Z}=-0,5) \mathrm{e}$ pouco reduzidas de IGF-l $(15 \mathrm{l} \mu \mathrm{g} / \mathrm{L}, \mathrm{Z}=-2)$ (Tabela 1). Durante o teste de geração não foi observado aumento nos valores de IGF-l (basal $=100 \mu \mathrm{g} / \mathrm{L}$; após 4 dias de $\mathrm{hGH}=94 \mu \mathrm{g} / \mathrm{L}$ ) e IGFBP-3 (basal = 3,1 mg/L; após 4 dias de $\mathrm{hGH}=2,5 \mathrm{mg} / \mathrm{L}$ ). Os valores de GHBP eram reduzidos neste paciente, porém detectáveis.

Foi feito diagnóstico clínico e laboratorial de IGH. Os valores, relativamente elevados, de IGF-1 e IGFBP-3 nesta segunda avaliação, com o paciente já em puberdade, foram interpretados como causados pela ação dos esteróides sexuais $($ testosterona $=193 \mathrm{ng} / \mathrm{dL} ; \mathrm{LH}=$ $6,3 \mathrm{U} / \mathrm{L}$ e $\mathrm{FSH}=9,8 \mathrm{U} / \mathrm{L}$ ). Aumento discreto nas concentrações de IGF-1 e IGFBP-3, durante a puberdade, em crianças com IGH já foi demonstrado anteriormente (11) e pode refletir secreção de IGF-1 e IGFBP-3, independentemente de GH ou melhora na ação do GH pelo aumento da testosterona e/ou, mais provavelmente, do estrógeno (12).

O paciente em questão foi, inicialmente, tratado com a administração de análogo do GnRH (aGnRH) para bloqueio da puberdade, enquanto aguardava o início do tratamento com IGF-1 recombinante humano (hIGF-1). Durante o bloqueio da puberdade foi observada redução nos níveis de IGF-1 e IGFBP-3 que voltaram a se elevar quando o tratamento foi suspenso e a puberdade reiniciada (Tabela 1), reforçando a idéia de que haveria atenuação da resistência ao $\mathrm{GH}$ promovida pelos esteróides sexuais. 


\section{INVESTIGAÇÃO MOLECULAR DA IGH}

A alteração molecular mais encontrada na IGH é a mutação no gene do receptor de GH (GHR) (13). Menos freqüentemente, ocorrem mutações no gene do $\mathrm{GH}$ (GHI) com geração de molécula de GH biologicamente inativa (14), ou na STAT5b que provoca defeito pósreceptor de GH (13) (Tabela 5). Defeitos isolados da síntese ou ação do IGF-1 apresentam algumas características laboratoriais semelhantes à IGH, porém apresentam quadro clínico distinto (15-18) (Tabela 5).

\section{Receptor de hormônio de crescimento (GHR)}

$\mathrm{O}$ GH realiza as suas ações por meio de sua interação com o receptor de membrana pertencente à superfamília dos receptores de citocinas/hematopoetina, o GHR (19). O GHR possui um único domínio transmembrânico e não apresenta atividade enzimática intrínseca, necessitando estar associado, na sua porção intracitoplasmática, à proteína com atividade de tirosina quinase, conhecida como Janus quinase 2 (JAK2), para que ocorra a transdução do sinal intracelular (19). O primeiro e crucial passo na transdução do sinal do GH consiste da sua ligação a dois GHR que se encontram pré-dimerizados na superfície celular (20). Esta ligação promove alteração na conformação espacial da porção intracitoplasmática do GHR, que ocasiona a interação entre as proteínas JAK2. Esta proximidade entre duas JAKs leva uma a fosforilar os resíduos de tirosina localizados no domínio quinase da outra. Uma vez fosforilada, a JAK2 passa a fosforilar múltiplos resíduos de tirosina presentes no GHR, gerando sítios de acoplamento para outras moléculas sinalizadoras (19). O GHR e a JAK2 ativam diversas vias de sinalização comuns a vários receptores com atividade quinase. Entre as vias ativadas pelo GHR, a mais importante, em relação aos efeitos de regular a síntese e a secreção de IGF-1 e assim regular o crescimento pós-natal, utiliza proteínas citoplasmáticas chamadas signal transducer and activators of transcription (STATs) (19). Várias STATs são ativadas após a ativação do GHR, mas as STATs $5 \mathrm{a}$ e $5 b$ são as que exercem papel principal na transdução do sinal do GHR (19). Por intermédio destas múltiplas vias de sinalização intracelular, o GH promove proliferação celular e induz à síntese de IGF-1, da sua proteína ligadora (IGFBP-3) e da subunidade ácido-lábil (ALS).

Tabela 5. Genótipo e fenótipo dos defeitos no eixo GH/IGF-1, excluindo a deficiência de GH.

\begin{tabular}{|c|c|c|c|c|c|c|c|c|}
\hline \multirow[t]{2}{*}{ Defeito } & \multicolumn{2}{|c|}{ Genótipo } & \multicolumn{2}{|c|}{ Crescimento } & \multicolumn{3}{|c|}{ Dosagens hormonais } & \multirow{2}{*}{$\begin{array}{l}\text { Outras } \\
\text { Características }\end{array}$} \\
\hline & Gene & Mutação & Pré-natal & Pós-natal & GH & IGF-1 & IGFBP-3 & \\
\hline \multirow{3}{*}{$\begin{array}{l}\text { Insensibilidade } \\
\text { ao GH }\end{array}$} & GHR & Homozigose & $\mathrm{NI}$ ou $\downarrow$ & $\downarrow \downarrow a \downarrow \downarrow \downarrow$ & NI ou $\uparrow \uparrow$ & $\downarrow a \downarrow \downarrow \downarrow$ & $\downarrow a \downarrow \downarrow \downarrow$ & $\begin{array}{l}\text { Fenótipo da síndrome de Laron } \\
\text { presente ou ausente. }\end{array}$ \\
\hline & STAT5b & Homozigose & NI ou $\downarrow$ & $\downarrow \downarrow \downarrow$ & $\uparrow \uparrow$ & $\downarrow \downarrow$ & $\downarrow \downarrow$ & $\begin{array}{l}\text { Fenótipo leve da síndrome de } \\
\text { Laron, com ou sem } \\
\text { imunodeficiência. Níveis de PRL } \\
\text { elevados. }\end{array}$ \\
\hline & GHI & $\begin{array}{l}\text { Homozigose e } \\
\text { heterozigose }\end{array}$ & NI ou $\downarrow$ & $\downarrow \downarrow \downarrow$ & $\uparrow \uparrow$ & $\downarrow \downarrow$ & $\downarrow \downarrow$ & $\begin{array}{l}\text { Fenótipo leve da síndrome de } \\
\text { Laron. Molécula de } \mathrm{GH} \\
\text { biologicamente inativa. }\end{array}$ \\
\hline \multirow{2}{*}{$\begin{array}{l}\text { Deficiência } \\
\text { isolada de IGF-1 }\end{array}$} & \multirow[t]{2}{*}{$|G F|$} & Homozigose & $\downarrow \downarrow \downarrow$ & $\downarrow \downarrow \downarrow$ & $\uparrow \uparrow$ & $\downarrow \downarrow \downarrow \downarrow$ & $\mathrm{Nl} \mathrm{ou} \uparrow$ & \multirow{2}{*}{$\begin{array}{l}\text { Microcefalia, micrognatia, } \\
\text { surdez sensorial, atraso no } \\
\text { DNPM, retardo mental, } \\
\text { resistência à insulina. }\end{array}$} \\
\hline & & Heterozigose & $\mathrm{NI} a \downarrow$ & $\mathrm{NI} a \downarrow$ & - & $\mathrm{NI} a \downarrow$ & $\mathrm{NI}$ & \\
\hline \multirow{2}{*}{$\begin{array}{l}\text { IGF-1 } \\
\text { biologicamente } \\
\text { inativo }\end{array}$} & \multirow[t]{2}{*}{$|G F|$} & Homozigose & $\downarrow \downarrow \downarrow$ & $\downarrow \downarrow \downarrow$ & $\uparrow \uparrow$ & $\uparrow \uparrow \uparrow \uparrow$ & $\mathrm{NI}$ & \multirow{2}{*}{$\begin{array}{l}\text { Microcefalia, micrognatia, } \\
\text { surdez sensorial, atraso no } \\
\text { DNPM, retardo mental, } \\
\text { resistência à insulina. }\end{array}$} \\
\hline & & Heterozigose & $\mathrm{NI}$ & $\mathrm{NI} a \downarrow$ & - & $\mathrm{NI} a \uparrow$ & - & \\
\hline \multirow{2}{*}{$\begin{array}{l}\text { Insensibilidade } \\
\text { isolada ao IGF-1 }\end{array}$} & \multirow[t]{2}{*}{$I G F I R$} & Homozigose & $\downarrow \downarrow \downarrow$ & $\downarrow \downarrow \downarrow$ & $\uparrow \uparrow$ & $\uparrow \uparrow$ & $\mathrm{NI} a \uparrow \uparrow$ & \multirow{2}{*}{$\begin{array}{l}\text { Microcefalia, micrognatia, } \\
\text { atraso no DNPM, retardo mental } \\
\text { nem sempre presente, } \\
\text { resistência à insulina. }\end{array}$} \\
\hline & & Heterozigose & $\mathrm{NI} a \downarrow \downarrow$ & NI $a \downarrow \downarrow$ & $\mathrm{Nla} \uparrow$ & $\mathrm{Nla} \uparrow$ & $\mathrm{NIa} \uparrow$ & \\
\hline
\end{tabular}

$\mathrm{NI}=$ normal; $\uparrow=$ aumentada; $\downarrow=$ diminuída. 
$\mathrm{Na}$ maioria dos pacientes com IGH, mutações no GHR são encontradas em homozigose ou heterozigose composta. Mais de 40 mutações no GHR foram descritas em pacientes com IGH, a maioria localizada entre os exons 4 e 7 , que formam o domínio de ligação do GH. Com base nestes conhecimentos, obteve-se DNA de sangue periférico do paciente e na seqüência o gene do GHR (exons 2 ao 10). No éxon 7 deste paciente, foi encontrada troca do nucleotídeo $\mathrm{G}$ pelo nucleotídeo $\mathrm{T}$ na segunda posição do codon 226 (AGT > ATT) em homozigose (12).

\section{INTERPRETANDO UM NOVO ACHADO MOLECULAR}

$\mathrm{Na}$ avaliação molecular, qualquer alteração encontrada na seqüência gênica pode significar mutação que explica o fenótipo ou pode representar apenas uma variante alélica que não tenha relação com o quadro clínico. Para interpretar corretamente a alteração na seqüência gênica de determinado gene, deve-se responder a uma série de perguntas que visam a caracterizar a importância da variante alélica em relação ao fenótipo do paciente:

\section{Existe descrição prévia da variante alélica encontrada?}

Para saber se a alteração na seqüência gênica observada no paciente em questão já foi previamente descrita na literatura, foram realizadas consultas a artigos sobre o assunto e em sites que organizam dados sobre a associação de doenças e mutações em seus respectivos genes. A busca em um desses sites (The Human Gene Mutation Database - http://www.hgmd.cf.ac.uk/ac/index.php) (21) mostrou que, das sete mutações já descritas no exon 7 do GHR associadas à IGH, nenhuma localizava-se no codon 226. Portanto, não existem descrições prévias da mutação que tenham sido encontradas no gene do GHR.

\section{A variante alélica descrita é observada em indivíduos normais?}

O próximo passo é verificar se a variante alélica encontrada no codon 226 pode ser encontrada em indivíduos saudáveis e assim ser considerada um polimorfismo. A resposta a esta pergunta pode ser encontrada em sites que organizam listas de polimorfismos para cada gene (22). Como, nos bancos de dados disponíveis, não havia descrição de polimorfismos na região do codon 226 , avaliou-se se esta alteração poderia ser específica para a população em análise, estudando o exon 7 do GHR em
200 alelos de crianças controles. Observou-se ausência de qualquer variante alélica neste lócus, indicando que a troca de AGT > ATT no codon 226 do GHR não é um polimorfismo. Entretanto, esses achados não estabelecem a relação de causa e efeito da alteração genética com o fenótipo do paciente e, para tanto, são necessários estudos funcionais do gene.

\section{Essa mutação segrega na família?}

Um dado que reforça a possibilidade de que a variante alélica encontrada seja a responsável pelo fenótipo do paciente é observar se ocorre segregação familiar, ou seja, se existe na família correlação entre o genótipo e o fenótipo. Ao estudar a família do paciente em questão, os cinco irmãos e a mãe são heterozigotos para a troca do nucleotídeo G por T no codon 226 e três irmãos carreiam apenas o alelo normal. A amostra de DNA do pai não foi disponível para estudo, mas pode-se inferir que ele também deva ser carreador da alteração alélica em heterozigose. Como a maioria dos casos de IGH é de herança autossômica recessiva, a presença da mutação em homozigose exclusivamente no paciente e sua ausência ou presença em heterozigose nos familiares não afetados são dados que reforçam a possibilidade de que a alteração genética encontrada seja causadora da IGH.

\section{Qual é o mecanismo pelo qual a mutação causa a doença?}

O passo seguinte, na investigação molecular, é evidenciar o mecanismo por meio do qual a mutação encontrada cause perda da função do receptor de GH. As possibilidades são: a) a mutação encontrada está na região codificadora do gene $G H R$, no exon 7, podendo tratar-se de uma mutação missense, que altera um único aminoácido importante para a função da proteína; b) a mutação altera o processo normal de splicing, causando alteração importante no RNA mensageiro (RNAm).

Em relação a esta última possibilidade, ressalte-se que os genes eucarióticos, em sua maioria, são organizados em exons (seqüências que codificam uma proteína) e introns (seqüências não codificadoras que se encontram entre cada exon). Após a síntese de determinado RNAm, uma cópia da seqüência genômica contendo os exons e introns, ocorre, no núcleo da célula, processo de remoção dos in trons conhecido como splicing. Uma alteração na seqüên cia de DNA de determinado gene pode causar mudanças no processamento do RNAm, levando a excluir um exon ou incluir uma porção do intron na seqüência de RNAm, modificando completamente a proteína sintetizada e, as- 
sim, causando uma doença. Foi checada se a troca do nucleotídeo G por T no codon 226, encontrada no paciente em análise, poderia alterar o processamento do RNAm por meio da simulação do processo de splicing em modelos matemáticos disponíveis (23). Os resultados indicaram que a troca de $\mathrm{G}>\mathrm{T}$ encontrada não alterava o processamento do RNAm do gene do GHR.

\section{Se a alteração encontrada não prejudica o processamento do RNAm, ela poderia modificar o aminoácido traduzido?}

Na seqüência de referência do codon 226 tem-se os nucleotídeos AGT que codificam o aminoácido serina (S). Já no paciente em estudo foi encontrado neste codon a seqüência ATT, que codifica o aminoácido isoleucina (I). Ao encontrar a mutação que troca o aminoácido de determinada proteína, é necessário compreender qual seja a repercussão desta troca na estrutura da proteína. Isso vai depender principalmente da localização da mutação e da mudança das propriedades físico-químicas causadas pela troca do aminoácido. A mutação S226I localiza-se na porção extracelular do receptor de $\mathrm{GH}$ em uma região extremamente conservada entre receptores de $\mathrm{GH}$ de diferentes espécies e também entre outros receptores de citoquinas. Esta região é conhecida como WSXWS-like motif por ser constituída de um aminoácido aromático (triptofano - $\mathrm{W}$ ou tirosina $-\mathrm{Y}$ ), um aminoácido pequeno (serina $-\mathrm{S}$ ou glicina $-\mathrm{G}$ ), qualquer aminoácido $(\mathrm{X})$, seguido por outro aminoácido aromático (triptofano - $\mathrm{W}$ ou fenilalanina - F) e, por último, uma serina (S), que é o aminoácido mais conservado nesta região. Esta seqüência tem grande importância no tráfego dos receptores de citoquinas do retículo endoplasmático para a membrana celular (24). O codon 226 é responsável justamente por codificar este último aminoácido. O paciente em questão apresenta nesta posição a troca de serina (um aminoácido hidrofilico, polar e com peso molecular 87) pelo aminoácido isoleucina (que é hidrofóbico, apolar e com peso molecular 113). Com base nas diferenças entre os dois aminoácidos e da natureza extremamente conservada deste resíduo, pode-se prever que a mutação S226I altera de maneira importante a estrutura e a função desta região do receptor de $\mathrm{GH}$.

\section{Existem estudos funcionais ou modelos animais que demonstrem o efeito da mutação encontrada na função do GHR?}

O último passo na investigação molecular é a realização de estudo funcional ou a criação de modelos animais com a mutação que fornecerão evidências definitivas para associar a alteração gênica em investigação com a doença. Hilton e cols. avaliaram a função dos aminoácidos que compõem a região WSXWS e demonstraram que quando se troca a serina 236 do receptor de eritropoetina (EPOR), posição equivalente à serina 226 do receptor de $\mathrm{GH}$, por isoleucina, ocorre perda completa da expressão do EPOR na superfície celular (25). Adicionalmente, um estudo com modelo animal de IGH em galinhas observou que galinhas portadoras de IGH apresentavam mutação na última serina da seqüência WSXWS, e estudos funcionais utilizando o receptor de GH humano mostrava que a mutação S226I ocasiona diminuição na expressão do GH (26).

\section{INSENSIBILIDADE AO HORMÔNIO DE CRESCIMENTO NO BRASIL}

No Brasil, já foram descritos 13 pacientes com IGH, pertencentes a dez famílias. Os dois primeiros pacientes, irmãos nascidos de pais primos de primeiro grau de origem italiana, apresentavam história clínica de hipoglicemia neonatal e fenótipo clássico de IGH, e foram descritos por Saldanha e Toledo, em 1981 (27). O defeito molecular deste primeiro caso foi elucidado por Berg e cols. como a mutação no intron $6 \mathrm{em}$ um sítio conservado e importante para o processo de splice (28). O Laboratório de Hormônios e Genética Molecular LIM/42 da Disciplina de Endocrinologia da FMUSP esclareceu o defeito molecular de dez pacientes com IGH (29). Em um paciente descrito, inicialmente, por Bandeira e cols. (30) foi observada mutação nonsense em homozigose no exon 5 (Y95X) (31). Em oito pacientes de seis famílias foi observada a mesma mutação em homozigose no exon 6 do GHR, a E180splice (29). Esta mesma mutação foi descrita em pacientes com IGH originários do Equador (32) e de Israel (33), demonstrando que ela apresenta efeito fundador entre estas famílias e, finalmente, o paciente apresentado neste relato de caso (12). Todos estes pacientes apresentam fenótipo clássico, descrito por Laron e, provavelmente, outros pacientes com formas atípicas estejam sendo subdiagnosticados no meio em que vivemos.

\section{NOVOS DEFEITOS MOLECULARES DA IGH}

A presença de IGH por defeitos pós-receptor foi proposta, pela primeira vez, no final da década de 1990 
$(34,35)$. Recentemente, foram descritos pacientes com IGH causada por mutações inativadoras da STAT5b, gene que traduz a molécula-chave na transdução do sinal via GHR (13). Estas crianças apresentavam baixa estatura importante, resistente ao tratamento com hGH, associada a quadro clínico variável de síndrome de Laron e presença de alterações imunológicas caracterizadas por infecções pulmonares de repetição e quadros infecciosos de herpes-zóster ou varicela (13). Laboratorialmente, estes pacientes apresentavam perfil hormonal clássico observado em pacientes com IGH, exceto por níveis normais de GHBP (13).

Em 2007, foi descrito um paciente com IGH portador de mutação da $S T A T 5 b$ que não apresentava alteração imunológica evidente (36), indicando que mutações da $S T A T 5 b$ levam a espectro fenotípico variável, desde quadros mais leves a mais graves. Neste artigo foi mostrado que o paciente apresentava, além do GH elevado, como seria de se esperar em um paciente com IGH, valores de prolactina (PRL) muito aumentados $(110 \mu \mathrm{g} / \mathrm{L})$, com ampliação da intensidade dos pulsos e da secreção basal de PRL (36). Tal achado foi confirmado nos casos descritos anteriormente. Assim, a presença de PRL elevada em um paciente com IGH aponta presença de defeitos da STAT5b.

\section{DISCUSSÃo}

\section{Nicolau Lima Neto}

(Serviço de Endocrinologia e Metabologia do HCFMUSP)

Você mostrou grande variabilidade nos valores de GH basal e após estímulo, no caso apresentado, assim como entre os pacientes com o diagnóstico de IGH. Existe correlação entre estes valores laboratoriais e a gravidade de IGH?

\section{Alexander Augusto de Lima Jorge}

Os trabalhos que avaliaram a relação genótipo-fenótipo mostraram que pacientes que têm a forma atípica apresentam valores de $\mathrm{GH}$ com maior freqüência dentro da normalidade. No nosso paciente, observamos um dado interessante: em idade pré-púbere ele apresentava quadro clínico e laboratorial típico da síndrome de Laron, mas quando foi avaliado em idade puberal, os valores de IGF-1 e IGFBP-3 estavam próximos ou dentro da normalidade, e por diversas vezes os valores basais de GH foram baixos, o que não favorecia a hipótese diagnóstica de IGH. Podemos concluir que, além da variabilidade na apresentação clínica e laboratorial, dependendo do defeito molecular que os pacientes com IGH possam apresentar, outros fatores, como a puberdade, também podem modificar o perfil laboratorial desses pacientes.

\section{Marcello Delano Bronstein}

(Serviço de Endocrinologia e Metabologia HCFMUSP)

Você mostrou que $75 \%$ dos casos de IGH cursam com valores baixos de GHBP, mas existem 25\% dos casos de síndrome de Laron que apresentam concentrações normais ou elevadas deste peptídeo. Qual seria a explicação para GHBP elevada nestes pacientes?

\section{Alexander Augusto de Lima Jorge}

A GHBP é produzida pela clivagem do GHR presente na superfície celular e suas concentrações refletem a expressão deste receptor. Os valores de GHBP encontram-se normais nos casos de IGH causados por mutações no domínio transmembrânico (37) ou na porção intracitoplasmática (38) do GHR. Tais mutações não interferem na expressão do receptor, nem na sua capacidade de se ligar ao GH, mas impedem a transdução do sinal do GH para o compartimento intracelular. De modo semelhante, defeitos pós-receptor, como as recém-descritas mutações na $S T A T 5 b$, acarretam IGH com concentrações de GHBP dentro de valores normais, pois não interferem na expressão do GHR na superfície celular e na gênese da GHBP.

\section{Marcello Delano Bronstein}

O outro ponto que me chamou a atenção é a elevação da prolactina (PRL) nos casos de IGH, causados por mutações da STAT5b. O nível elevado de GH faz sentido pela ausência do feedback negativo exercido pelo IGF-1 sobre a secreção de GH. Mas como explicar os níveis elevados de PRL nestes pacientes?

\section{Alexander Augusto de Lima Jorge}

A explicação, dada pelos autores que descreveram esta associação, é de que o excesso de secreção de GHRH nestes pacientes estimularia a secreção de GH e de PRL (36). Os modelos animais de hiperexpressão de GHRH (39) ou os indivíduos que têm tumores produtores de GHRH (40) apresentam aumento da secreção destes dois hormônios. Porém, não se observa o aumento da PRL nos pacientes com IGH por mutações no $R G H$. Outra possibilidade 
seria a diminuição do auto-feedback negativo que a prolactina exerce sobre a sua própria secreção. A mutação da STAT5b levaria à redução nesta auto-inibição e, assim, aumentaria os níveis de PRL. Ambas as hipóteses necessitam de comprovação em estudos futuros.

\section{Bernardo Léo Wajchenberg}

\section{(Faculdade de Medicina da USP)}

Há casos descritos da mutação E180splice em Portugal ou nas antigas colônias portuguesas?

\section{Alexander Augusto de Lima Jorge}

Não. Até o presente, a mutação E180splice foi descrita, somente, no Equador, em judeus originários de Marro$\cos \mathrm{e}$, agora, no Brasil. É mais provável que a mutação seja originária da Espanha, de judeus que durante a inquisição fugiram para as colônias na América do Sul, diretamente, ou por Portugal (41).

\section{Luiz Roberto Salgado}

(Serviço de Endocrinologia e Metabologia HCFMUSP)

Estudos mostram grande variabilidade dos valores de GHBP em indivíduos normais e também nos pacientes com IGH. Como você avalia o uso da dosagem de GHBP já que é tão variável dentro de condições clínicas distintas?

\section{Alexander Augusto de Lima Jorge}

Um primeiro ponto é que a GHBP varia com a idade e seus valores devem ser interpretados de acordo com a faixa etária. Nem todos os pacientes com IGH apresentam GHBP baixa. Mas, por outro lado, a principal causa de GHBP reduzida na ausência de doença hepática é a presença de mutações no GHR, causando IGH. Attie e cols. avaliaram 511 crianças com baixa estatura idiopática (BEI) e verificaram que $20 \%$ apresentavam níveis de GHBP inferiores ao normal para idade e sexo (42). Estudo subseqüente identificou mutações no GHR em $14 \%$ das crianças com BEI e com GHBP baixos (4). Estes dados sugerem que a GHBP poderia ser utilizada para selecionar, entre as crianças com BEI, as possíveis portadoras de mutações no GHR. Porém, a dosagem de GHBP não é rotineira em nosso meio e está restrita a protocolos de pesquisa.

Agradecimentos: $\mathrm{O}$ estudo molecular foi realizado com o auxílio financeiro da Fundação de Amparo Pesquisa do Estado de São Paulo (Fapesp) - Projeto Temático $n^{\circ}$ 05/04726-0. AALJ possui auxílio do Conselho Nacional de Pesquisa (CNPq) $n^{\circ} 307951 / 2006-5$. O autor gostaria de agradecer seus colaboradores, Damiani $\mathrm{D}$, Lins TSS e Bandeira F, pelo envio de amostras para o estudo molecular.

\section{REFERÊNCIAS}

1. Sizonenko PC, Clayton PE, Cohen P, Hintz RL, Tanaka T, Laron Z. Diagnosis and management of growth hormone deficiency in childhood and adolescence. Part 1: diagnosis of growth hormone deficiency. Growth Horm IGF Res. 2001;11:137-65.

2. Laron Z. Laron syndrome (primary growth hormone resistance or insensitivity): the personal experience 1958-2003. J Clin Endocrinol Metab. 2004;89:1031-44.

3. Amselem S, Duquesnoy P, Duriez B, Dastot F, Sobrier ML, Valleix $S$, et al. Spectrum of growth hormone receptor mutations and associated haplotypes in Laron syndrome. Hum Mol Genet. 1993;2:355-9.

4. Goddard AD, Covello R, Luoh SM, Clackson T, Attie KM, Gesundheit $\mathrm{N}$, et al. Mutations of the growth hormone receptor in children with idiopathic short stature. The Growth Hormone Insensitivity Study Group. N Engl J Med. 1995;333:1093-8.

5. Blum WF, Cotterill AM, Postel-Vinay MC, Ranke MB, Savage MO, Wilton P. Improvement of diagnostic criteria in growth hormone insensitivity syndrome: solutions and pitfalls. Pharmacia Study Group on Insulin-like Growth Factor I Treatment in Growth Hormone Insensitivity Syndromes. Acta Paediatr Suppl. 1994;399:117-24.

6. Savage MO, Blair JC, Jorge AJ, Street ME, Ranke MB, Camacho-Hubner C. IGFs and IGFBPs in GH insensitivity. Endocr Dev. 2005;9:100-6.

7. Woods KA, Clark AJ, Amselem S, Savage MO. Relationship between phenotype and genotype in growth hormone insensitivity syndrome. Acta Paediatr Suppl. 1999;88:158-62; discussion 163.

8. Baumann G. Growth hormone binding protein 2001. J Pediatr Endocrinol Metab. 2001;14:355-75.

9. Toyoshima MT, Castroneves LA, Costalonga EF, Mendonça BB, Arnhold IJ, Jorge AA. Exon 3-deleted genotype of growth hormone receptor (GHRd3) positively influences IGF-1 increase at generation test in children with idiopathic short stature. Clin Endocrinol (Oxf). 2007.

10. Jorge AA, Souza SC, Arnhold IJ, Mendonça BB. Poor reproducibility of IGF-I and IGF binding protein-3 generation test in children with short stature and normal coding region of the GH receptor gene. J Clin Endocrinol Metab. 2002;87:469-72.

11. Rosenbloom AL, Guevara Aguirre J, Rosenfeld RG, Fielder PJ. The little women of Loja--growth hormone-receptor deficiency in an inbred population of southern Ecuador. N Engl J Med. 1990;323:1367-74.

12. Jorge AA, Souza SC, Arnhold IJ, Mendonça BB. The first homozygous mutation (S226I) in the highly-conserved WSXWSlike motif of the $\mathrm{GH}$ receptor causing Laron syndrome: supression of $\mathrm{GH}$ secretion by $\mathrm{GnRH}$ analogue therapy not restored by dihydrotestosterone administration. Clin Endocrinol (Oxf). 2004;60:36-40.

13. Rosenfeld RG, Belgorosky A, Camacho-Hubner C, Savage MO, Wit JM, Hwa V. Defects in growth hormone receptor signaling. Trends Endocrinol Metab. 2007;18:134-41.

14. Besson A, Salemi S, Deladoey J, Vuissoz JM, Eble A, Bidlingmaier $M$, et al. Short stature caused by a biologically inactive 
mutant growth hormone (GH-C53S). J Clin Endocrinol Metab. 2005;90:2493-9.

15. Walenkamp MJ, van der Kamp HJ, Pereira AM, Kant SG, van Duyvenvoorde HA, Kruithof MF, et al. A variable degree of intrauterine and postnatal growth retardation in a family with a missense mutation in the insulin-like growth factor I receptor. J Clin Endocrinol Metab. 2006;91:3062-70.

16. Walenkamp MJ, Karperien M, Pereira AM, Hilhorst-Hofstee $Y$, van Doorn J, Chen JW, et al. Homozygous and heterozygous expression of a novel insulin-like growth factor-I mutation. J Clin Endocrinol Metab. 2005;90:2855-64.

17. Abuzzahab MJ, Schneider A, Goddard A, Grigorescu F, Lautier C, Keller E, et al. IGF-I receptor mutations resulting in intrauterine and postnatal growth retardation. $N$ Engl J Med. 2003:349:2211-22.

18. Woods KA, Camacho-Hubner C, Savage MO, Clark AJ. Intrauterine growth retardation and postnatal growth failure associated with deletion of the insulin-like growth factor I gene. N Engl J Med. 1996;335:1363-7.

19. Kopchick JJ, Andry JM. Growth hormone (GH), GH receptor, and signal transduction. Mol Genet Metab. 2000;71:293-314.

20. Brown RJ, Adams JJ, Pelekanos RA, Wan Y, McKinstry WJ, Palethorpe K, et al. Model for growth hormone receptor activation based on subunit rotation within a receptor dimer. Nat Struct Mol Biol. 2005;12:814-21.

21. Stenson PD, Ball EV, Mort M, Phillips AD, Shiel JA, Thomas NS, et al. Human Gene mutation database (HGMD): 2003 update. Hum Mutat. 2003;21:577-81.

22. Barnes MR. Navigating the HapMap. Brief Bioinform. 2006; 7:211-24.

23. Reese MG, Eeckman FH, Kulp D, Haussler D. Improved splice site detection in Genie. J Comput Biol. 1997;4:311-23.

24. Yoshimura A, Zimmers T, Neumann D, Longmore G, Yoshimura Y, Lodish HF. Mutations in the Trp-Ser-X-Trp-Ser motif of the erythropoietin receptor abolish processing, ligand binding, and activation of the receptor. J Biol Chem. 1992;267:11619-25.

25. Hilton DJ, Watowich SS, Katz L, Lodish HF. Saturation mutagenesis of the WSXWS motif of the erythropoietin receptor. J Biol Chem. 1996;271:4699-708.

26. Duriez B, Sobrier ML, Duquesnoy $P$, Tixier-Boichard M, Decuypere $\mathrm{E}$, Coquerelle $\mathrm{G}$, et al. A naturally occurring growth hormone receptor mutation: in vivo and in vitro evidence for the functional importance of the WS motif common to all members of the cytokine receptor superfamily. Mol Endocrinol. 1993;7:806-14.

27. Saldanha PH, Toledo SP. Familial dwarfism with high IR-GH: report of two affected sibs with genetic and epidemiologic considerations. Hum Genet. 1981;59:367-72.

28. Berg MA, Argente J, Chernausek S, Gracia R, Guevara-Aguirre $\mathrm{J}$, Hopp M, et al. Diverse growth hormone receptor gene mutations in Laron syndrome. Am J Hum Genet. 1993;52:998-1005.

29. Jorge AA, Menezes Filho HC, Lins TS, Guedes DR, Damiani D, Setian N, et al. [Founder effect of E180splice mutation in growth hormone receptor gene (GHR) identified in Brazilian patients with GH insensitivity]. Arq Bras Endocrinol Metabol. 2005;49:384-9.

30. Bandeira F, Camargo K, Caldas G, Rosenbloom A, Stabler B, Underwood L. Primary growth hormone insensitivity syndrome - a case report. Arq Bras Endocrinol Metabol. 1997;41:198-200.

31. Jorge AA, Bandeira F, Mendonça BB, Arnhold IJ. A novel nonsense mutation in growth hormone receptor gene (Y5X) in a brazilian patient with Iaron syndrome. J Pediatr Endocrinol Metab. 2004;17:1345.

32. Berg MA, Guevara-Aguirre J, Rosenbloom AL, Rosenfeld RG, Francke $U$. Mutation creating a new splice site in the growth hormone receptor genes of 37 Ecuadorean patients with Laron syndrome. Hum Mutat. 1992;1:24-32.

33. Berg MA, Peoples R, Perez-Jurado L, Guevara-Aguirre J, Rosenbloom AL, Laron Z, et al. Receptor mutations and haplotypes in growth hormone receptor deficiency: a global survey and identification of the Ecuadorean E180splice mutation in an oriental Jewish patient. Acta Paediatr Suppl. 1994;399:112-4.

34. Freeth JS, Ayling RM, Whatmore AJ, Towner P, Price DA, Norman MR, et al. Human skin fibroblasts as a model of growth hormone $(\mathrm{GH})$ action in $\mathrm{GH}$ receptor-positive Laron's syndrome. Endocrinology. 1997;138:55-61.

35. Freeth JS, Silva CM, Whatmore AJ, Clayton PE. Activation of the signal transducers and activators of transcription signaling pathway by growth hormone $(\mathrm{GH})$ in skin fibroblasts from normal and GH binding protein-positive Laron Syndrome children. Endocrinology. 1998;139:20-8.

36. Vidarsdottir S, Walenkamp MJ, Pereira AM, Karperien M, van Doorn J, van Duyvenvoorde HA, et al. Clinical and biochemical characteristics of a male patient with a novel homozygous STAT5b mutation. J Clin Endocrinol Metab. 2006;91:3482-5.

37. Woods KA, Fraser NC, Postel-Vinay MC, Savage MO, Clark AJ. A homozygous splice site mutation affecting the intracellular domain of the growth hormone $(\mathrm{GH})$ receptor resulting in Laron syndrome with elevated GH-binding protein. J Clin Endocrinol Metab. 1996;81:1686-90.

38. lida K, Takahashi Y, Kaji H, Takahashi MO, Okimura Y, Nose O, et al. Functional characterization of truncated growth hormone $(G H)$ receptor- (1-277) causing partial GH insensitivity syndrome with high GH-binding protein. J Clin Endocrinol Metab. 1999;84:1011-6.

39. Grattan DR, Xu J, McLachlan MJ, Kokay IC, Bunn SJ, Hovey $R C$, et al. Feedback regulation of PRL secretion is mediated by the transcription factor, signal transducer, and activator of transcription 5b. Endocrinology. 2001;142:3935-40.

40. Sano T, Asa SL, Kovacs K. Growth hormone-releasing hormone-producing tumors: clinical, biochemical, and morphological manifestations. Endocr Rev. 1988;9:357-73.

41. Guerra Junior G. [New christians in the Northeast area and the dwarfs of Orobo, Pernambuco, Brazil: a the molecular genetic linked to History of Brazill. Arq Bras Endocrinol Metabol. 2005;49:337-8.

42. Attie KM, Carlsson LM, Rundle AC, Sherman BM. Evidence for partial growth hormone insensitivity among patients with id iopathic short stature. The National Cooperative Growth Study. J Pediatr. 1995:127:244-50

Endereço para correspondência:

Alexander Augusto de Lima Jorge

Av. Dr. Enéas de Carvalho Aguiar, 155, $2^{\circ}$ andar, bloco 6

05403-900 São Paulo, SP

E-mail: alexj@pq.cnpq.br 